\title{
On Teaching of English Speaking to College Freshmen
}

\author{
Xiaoyan LI \\ Wuhan Institute of Technology, 430205, Wuhan
}

\begin{abstract}
College freshmen have their own characteristics in oral English including lack of accuracy, fluency and inappropriate communication. In order to improve their ability of English speaking, teachers can first adapt freshmen to the new teaching model, then choose proper teaching material, next treat their mistakes correctly and cultivate their crosscultural awareness at the same time.
\end{abstract}

Keywords: English speaking; teaching material; teaching model; crosscultural

\section{Introduction}

College English Curriculum Requirements sets higher demands to cultivate students' ability to use English in a well-rounded way, especially puts forward higher requirement to improve their ability in listening and speaking, so more importance is attached to teaching of English speaking. College freshmen's oral English is still at a starting stage, with students having strong desire to speak English yet being too afraid of making mistakes to open their mouths. Under the circumstances, a list of measures has to be taken in order to improve students' ability in oral English which include adapting students to the new teaching model, choosing proper teaching material, treating students' mistakes in an appropriate way, and cultivating students' crosscultural awareness.

\section{Characteristics of freshmen's oral English}

According to College English Curriculum Requirements, the basic requirements for speaking is that in the learning process, students can communicate with others in English, carry out discussion on a given subject, talk about daily topics with people from English-speaking countries, make a brief speech on a familiar topic after preparation, express their ideas clearly with basically right pronunciation and intonation, use the basic conversational strategies in talking with others. But the fact is that the majority of students have been learning English for at least six years before they enter universities. Most students can talk with others in English to a certain degree, have a good foundation to learn English further, and use English to greet others, do self-introduction, ask directions and do shopping, etc, but it can't be denied that they have a little or ever great difficulty in having a further discussion or dealing with more complex situations. Meanwhile, there are three main shortcomings in their oral expression.

First of all, students' oral expression is lacking in accuracy. Due to a limited vocabulary, freshmen are likely to express their ideas in a rather simple way. Sometimes they are not familiar with the collocation or the usage of words. One common mistake it to say "listen music" rather than "listen to music". Another example is to say "learn knowledge" instead of "acquire knowledge". The former is a typical Chinese English, which is known to all of us, but it sounds weird to English native speakers. With inappropriate words, what students say can't reflect their real meanings. On some occasions, there may exist grammatical mistakes, such as, the tense doesn't keep consistency in the context, the verb doesn't agree with the subject in person and number, articles are wrongly used, etc. It is beyond any doubt that the deficiency in vocabulary, grammar and 
syntactic knowledge has a negative influence on students' accuracy in oral communication. Therefore, students can't express their thoughts correctly.

Secondly, students' oral expression is lacking in fluency. If students write down what they want to say in advance and then read out what have been written, there won't be this problem. But done in this way, it is not spoken English. Instead, it is to read written English. As is known to all, spoken English is something people utter without doing any preparation. People may talk while thinking, or sometimes without thinking at all. That is why when speaking English, students may hesitate, repeat the same words, or stop to correct mistakes. This is another characteristic of freshmen's spoken English.

Finally, there are pragmatic mistakes. For example, students may use some casual language or even slang in a formal situation such as a job interview or a business negotiation. According to the author's years of teaching experience, a common mistake among freshmen is that when others give thanks to freshmen, they would respond with "thank you" too, which is obviously not appropriate in this situation.

\section{Measures to be taken}

Aiming at the above-mentioned characteristics, a list of measures may be taken in order to improve students' ability in oral English, among which are adapting freshmen to the new teaching model, choosing proper teaching material, treating students' mistakes correctly and cultivating students' crosscultural awareness.

\subsection{Adapting freshmen to the new teaching model}

Since high school students are under the pressure of college entrance examination, most English teachers in high schools adopt the traditional teacher-centered teaching model. Teachers arrange for everything for students' sake. It is teachers who decide the time, the place, the contents and even the way of learning, in which model students depend on teachers to a large degree. On the other side, because most focus is placed on language knowledge and skills, the majority of teachers in high school speak Chinese mandarin or even dialects in class.

Freshmen may find things are totally different in college. First of all, the teaching model is changing from teacher-centered to student-centered, which means it is students themselves that decide what and how to learn. Those who used to rely too much on teachers in high school may feel at a loss. Secondly, focus in college class is put on not only language knowledge and skills but also developing students' ability to use a language and to learn independently. It is easy to master language knowledge and skills. Therefore, students can gain satisfaction from success easily in high school. By contrast, it is difficult to develop one's ability in using a language, in which situation students feel frustrated. Next, teachers speak English most of the time, which without any doubt may be a great challenge to those having a poor foundation of English listening and speaking.

As a result, it is necessary for teachers to let students know the shift of teaching model, explain to students the new student-centered teaching philosophy, and adapt them to the new teaching model as soon as possible.

\subsection{Choosing proper teaching material}

In an English speaking class, if a natural language environment is created and more opportunities are provided for students to communicate with each other, it will effectively stimulate their interest and initiative. Consequently, students are more willing to practice their oral English. In order to achieve this goal, this first thing to be taken into consideration is to choose proper teaching material. 
Teaching material plays a very important role in teaching of English speaking. In most cases, all the tasks within a unit are in various forms and rich in content, but on the whole, all the units within a book have the same mode. Students may feel fun and exciting when they learn the first one or two units. But later, students may feel bored or even lose interest because they can predict the teaching procedure. In order to avoid this, two or more textbooks can be used at the same time. Based on different editing principles, each textbook has its own advantages and shortcomings. It is wise for teachers to choose at least two textbooks and make good use of them. Take Functioning in an Intercultural Community with Huadong Li being the chief editor and New Horizon English Speaking Listening Viewing with Shutang Zheng being the chief editor as examples. Based on functional-notional teaching approach and crosscultural communication theory, the former textbook is divided into a few units. Each unit conveys a specific function and provides students with a crosscultural theme which can meet their needs and arouse their interests. Most focus is put to improve students' ability of English speaking, with other skills such as listening, reading and writing also being considered. The latter textbook is designed and edited according to College English Curriculum Requirements. Students can improve their ability of listening and speaking by experiencing the real situation, listening to native language and doing various kinds of exercises. Multimedia technology is made full use of. Rich viewing and listening material and autonomous learning environment is provided to students. CDs complementary to the textbook contain all the relevant audio and video with a wide range of subjects, rich content and standard language, which can greatly stimulate students' interest and gradually improve their ability of listening and speaking. But looking at the screen for a long time gives students a visual fatigue and leads them to feel bored of study. So if the above-mentioned two textbooks are combined together, it may work well.

\subsection{Treating students' mistakes correctly}

Students may make many mistakes in their oral English. Some may be lost in words because of being too nervous. Some may stray far from the subject. Others may fail to convey their idea because of choosing wrong words. On these occasions, if teachers interrupt students or criticize them harshly, it will undermine their initiative in speaking undoubtedly.

The primary role that oral English teachers play in class is to help and encourage students to conduct a variety of activities and improve their English speaking level in different ways. Teachers help students to express their ideas accurately and fluently to develop a good habit of oral communication. With teachers' guidance and help, students can think clearly and convey their ideas fluently and logically. Teachers should treat students' mistakes in different ways, depending on the specific situation. For example, one student tells the teacher what he did last night by saying "we played happily last night", which is grammatically correct but not in accordance with English expression habit. In this case, the teacher may respond to the student by saying "oh, I see, you had a great time last night" or "well, you had a lot of fun last night." By repeating the student's idea with the right words and expressions, the student can realize his mistake and then correct it without feeling ashamed. If students make mistakes when doing some mechanical exercises of repetition or substitution, the teacher may point out their mistakes directly, which enables them to have a deep impression and avoid making the same mistakes again. When students are doing pair or group work, it is not desirable for the teacher to interrupt and correct their mistakes since the conversation is for communicative purpose. Constant mistake correction can interrupt their thoughts. Worse still, the student whose mistake is pointed out by the teacher may think he loses face in front his fellow students, which may undermine his enthusiasm and even lead him to keep silent in English speaking class. Therefore, 
it is of great importance to treat students' mistakes correctly.

\subsection{Cultivating students' crosscultural awareness}

Language is a carrier of culture and a tool for communication. An embarrassing truth is that some teachers forget to teach students to correctly use this tool to express their ideas, which lead to the phenomenon that students can convey what they think in a grammatically right way but wrongly in a crosscultural perspective. People from different countries have great differences in many aspects such as way of living, social background, education, belief, politics, economics, not to mention differences in personality, hobby and criterion of making friends. Hence, using Chinese thinking pattern to express cultures of English speaking countries will inevitably result in crosscultural shock. So it is necessary for teachers to develop students' sensibility to cultural differences and arouse their crosscultural awareness. To achieve this goal, foreign cultures including living habits, lifestyles, social customs and values should be introduced to students, which can stimulate students to learn foreign language and cultures as well. Meanwhile, by comparing the cultural differences between China and English countries and the differences in structures between Chinese and English language, teachers can give students insights into English cultures and English language, and enable them to understand their own cultures and language further.

\section{Conclusion}

The teaching objective of English speaking is to develop students' oral communicative competence. College freshmen, confronted with a new environment and a different teaching model, have unique features in their oral English, so it is important to choose proper textbooks. Teachers should treat students' mistakes correctly with an encouraging, friendly and tolerant attitude so as to create a relaxing class atmosphere. Modernized teaching facilities such as language labs, multimedia classrooms can be adopted to create a genuine language environment and motivate students. Students' crosscultural awareness also needs to be fostered. In addition, playing the multiple roles such as organizers, directors, participants, helpers and evaluators, teachers should improve their own language competence and comprehensive qualities. Only in this way can student's ability of English speaking be developed more effectively.

\section{References}

[1] Chundong Hu. English Teaching Methodology[M]. Beijing: Higher Education Press, 1990.

[2] Department of Higher Education. College English Curriculum Requirements[M]. Shanghai: Shanghai Foreign Language Education Press, 2007.

[3] Huadong Li. Functioning in an Intercultural Community[M]. Beijing: Foreign Language Teaching and Research Press, 2002.

[4] Jiarong Liu \& Yuhong Jiang. Investigation and Analysis of Discourse in Oral English Class[J]. Foreign Language Teaching and Research, 2004(4): 285-291.

[5] Jinfen Xu. Autonomy in College Foreign Language Learning: From Theory to Practice[M]. Beijing: China Social Sciences Press, 2007.

[6] Little, D. Learner Autonomy: Definitions, Issues and Problems[M]. Dublin: Authentic, 1991.

[7] Shutang Zheng. New Horizon English Speaking Listening Viewing[M]. Beijing: Foreign Language Teaching and Research Press, 2004. 
[8] Yuxin Jia. Intercultural Communication[M]. Shanghai: Shanghai Foreign Language Education Press, 1997.
[9] Zhenmin Ma. Oral Class and Its Pragmatic Model[J]. Foreign Language World, 2002(6): 49-53. 